\title{
Editorial
}

\section{Why the controversy about electron beam computed tomographic screening for coronary atherosclerosis?}

Electron beam cardiac computed tomography is being used to screen for occult coronary atherosclerosis. This procedure, which can detect small amounts of calcium phosphate in atherosclerotic vessels, is now available at 48 centres throughout the world.

Advocates of this type of screening state that coronary calcium signifies atherosclerosis, that detection of this deadly disease is important, and that a positive screen justifies aggressive management of risk factors or further evaluation by exercise testing or angiography. Others who are less convinced of its value do not think that it should be used to screen for coronary artery disease. ${ }^{1}$

This editorial summarises the strength of the evidence linking coronary calcium with atherosclerosis and coronary events and proposes a model for the future development of this technique.

\section{Evidence linking coronary calcium to atherosclerosis in dead and symptomatic study groups}

Necropsy studies support the contention that coronary calcium almost always signifies atherosclerosis. ${ }^{2-7}$ In 1961, Blankenhorn performed radiographic and histopathological studies of 89 randomly selected hearts. ${ }^{6}$ Thirty years later, Simons et al used electron beam tomography and careful histopathological sectioning to examine 13 hearts for coronary calcium deposits. ${ }^{7}$ Neither study found one calcified radio-opaque lesion that was not atherosclerotic.

Angiographic studies also support an association between calcium and stenoses in study groups with symptoms. Gianrossi et al performed a meta-analysis of the relation between fluoroscopically detectable coronary calcium and angiographic disease. ${ }^{8}$ The studies they reviewed used conventional image intensifier fluoroscopy in patients with symptoms who had angiography for clinical indications. They found that cardiac fluoroscopy was almost as accurate as exercise electrocardiography and exercise thallium scintigraphy. When electron beam tomography was compared with coronary angiography in patients with symptoms the sensitivity of electron beam tomography was about $100 \%$ but the specificity was lower than in fluoroscopic studies. ${ }^{9-11}$ Loecker et al performed a prospective fluoroscopic evaluation of 613 aircrewmen undergoing conventional fluoroscopy and angiography. ${ }^{12}$ The prevalence of angiographic narrowing in this healthy young cohort was about $17 \%$. This report is unique because these men had no symptoms. Loecker et al found a sensitivity of $66 \%$ and a specificity of $78 \%$ for the prediction of at least one angiographic luminal narrowing of at least $50 \%$.

\section{Coronary calcium as a predictor of events in symptom free groups}

The prevalence of coronary artery calcium detected by electron beam computed tomography is high and rises dramatically with age: more than $60 \%$ of symptom free women and $80 \%$ of symptom free men aged more than 60 have detectable calcium. ${ }^{1314}$ Because clinical coronary events will develop in only a small proportion of these individuals risk stratification depends on a defined amount of calcium being regarded as high risk. Because the amount of disease present when any calcification whatever is detected is so small the predictive value of the detection of coronary calcium is limited. Very few data link coronary artery calcium to an increased incidence of coronary events in those who are symptom free..$^{1516}$ These studies do show an increased risk of events in those with coronary calcium detected by fluoroscopy or by ultrafast computed tomography but the predictive values are no better than those independently reported for the exercise electrocardiogram. ${ }^{17} 18$

\section{A model for future research}

The problem of oversensitivity can be resolved if:

- Electron beam computed tomography accurately measures the mass of calcium precipitated in coronary arteries

- The mass of calcium corresponds with the amount of atherosclerosis

- The amount of atherosclerosis correlates with risk.

If these three conditions are met, reliable thresholds for a positive test can be set such that specificity and predictive value may be high enough to be useful.

\section{ACCURACY IN QUANTITATING CALCIUM MASS}

Though little work has been done to validate calcium measurements in coronary arteries an arbitrary scoring system has been proposed. ${ }^{19}$ More accurate methods are being developed and preliminary results are encouraging. ${ }^{20-23}$

\section{RELATION OF CALCIUM MASS WITH PATHOLOGY}

The best studies show an imperfect relation between the amount of calcium and the total atherosclerotic volume. ${ }^{74}$ Indeed, speculations that the mass of calcium may track the progression and regression of atherosclerosis are exciting ${ }^{25}$ but they have not been proved and more importantly the relation between clinical plaque stability and amount, morphology, or changes in coronary calcium is not clear. 
RELATION BETWEEN PATHOLOGY AND RISK

Though it is plausible that the amount of atherosclerosis is strongly related to risk this too is not proved. Nor is it known whether atherosclerosis is more or less malignant when it is calcified. ${ }^{26-30}$

\section{Coronary calcium and patients with symptoms}

In contrast to the symptom free individual, the usefulness of detecting coronary calcium in the patient with atypical angina is more firmly grounded. There are several well conducted studies using fluoroscopy and computed tomography. ${ }^{8-1119}$ When electron beam studies are negative in those with symptoms the probability of obstructive disease is low and such a result strongly suggests a noncardiac cause. Electron beam computed tomography may also be helpful in symptom free patients with abnormal exercise electrocardiograms. The absence of calcium in such patients suggests that the exercise result is a consequence of hyperventilation, ${ }^{31}$ medication, or an oestrogen effect. $^{32}$

\section{Reasons for the controversy}

On the one hand, a non-invasive tool is available which can detect even small amounts of a deadly pathology, coronary atherosclerosis. On the other, this tool is so sensitive that it detects atherosclerosis in many individuals who will never suffer its clinical consequences. This is not the only example of the dilemma of widespread potentially life threatening pathology which if it remains unrecognised usually runs a benign course. Clinically, thyroid carcinoma is rare; but Harach et al estimated that it would be diagnosed in nearly everyone aged over 50 if biopsies were sufficiently thorough. ${ }^{33}$ Fortunately, routine biopsy of the entire population has not been seriously proposed. Nor should the entire population be examined by electron beam computed tomography, which also would uncover pathology that is unlikely to become manifest.

Though it would be helpful to know whether calcium is present in those at intermediate risk of coronary disease (that is, with atypical angina or non-diagnostic exercise electrocardiograms), in those who are symptom free few clinical decisions can be based on these results. The presence of coronary calcium may alert a symptom free individual to a potential emerging problem, this supposed beneficial effect must be balanced against the detrimental effects of being labelled as ill, of anxiety, and of unwarranted invasive interventions.

\section{ROBERT C DETRANO St fohns Cardiovascular Research Center, Harbor-UCLA Medical Center, Building RB2, 1124 Carson Street, Torrance, California 90502, USA}

1 Committee on Advanced Cardiac Imaging and Technology, Council on Clinical Cardiology, and Committee on Newer Imaging Modalities, Council on Cardiovascular Radiology, American Heart Association. Potential value of ultrafast computed tomography to screen for coronary artery disease. Circulation 1993;87:2071-4.

2 Arnett EN, Isner JM, Redwood DR, Kent KM, Baker WP, Ackerstein H, Roberts WC. Coronary artery narrowing in coronary heart disease: Comparison of

3 Eggen DA, Strong JP, McGill HC. Coronary calcification: Relationship to clinically significant coronary lesions and race, sex, and topographic distribution. Circulation 1965;32:948-55.

4 Frink RJ, Achor RWP, Brown AL, Kincaid OW, Brandenburg RO. Significance of calcification of the coronary arteries. $\mathrm{Am} \mathcal{F}$ Cardio 1970;26:241-7.

5 Warburton RK, Tampas JP, Soule AB, Taylor HC. Coronary artery calci- fication: Its relationship to coronary artery stenosis and myocardial infarction. Radiology 1968;91:109-15.

6 Blankenhorn D. Coronary arterial calcification, a review. $\mathrm{Am} f \mathrm{Med} \mathrm{Sc}$ 1961; July;41-9.

7 Simons DB, Schwartz RS, Edwards WD, Sheedy PF, Breen JF Rumberger JA. Noninvasive definition of anatomic coronary artery disease by ultrafast computed tomographic scanning: A quantitative pathologic comparison study. $\mathcal{F}$ Am Coll Cardiol 1992;20:1118-26.

8 Gianrossi R, Detrano R, Colombo A, Froelicher V. Cardiac fluoroscopy for the diagnosis of coronary artery disease: A meta analytic review. $A m$ Heart $f$ 1990;120:1179-88.

9 Bormann JL, Stanford W, Stenberg RG, Winniford MD, Berbaum KS, Talman CL, Galvin JR. Ultrafast computed tomographic detection of coronary artery calcification as an indicator of stenosis. $\mathrm{Am} \mathcal{f}$ Cardia Imaging 1992;6:191-6.

10 Breen JF, Sheedy PF, Schwartz RS, Stanson AW, Kaufmann RB, Moll PP, Rumberger JA. Coronary artery calcification detected with ultrafas $\mathrm{CT}$ as an indication of coronary artery disease. Radiology 1992;185:435-9.

11 Georgiou D, Kennedy J, Brody A, Lewis R, Wolfkiel C, Agatston A, et al. Probability. of multivessel coronary artery disease in 531 patients based upon ultrafast CT coronary calcification: a multicenter study [abstr]. $\mathscr{F}$ Am Coll Cardiol 1994;179.

12 Loecker T, Schwartz R, Cotta C, Hickman J. Fluoroscopic coronary calcification and associated coronary disease in asymptomatic young men cification and associated coronary dis Coll Cardiol 1992;19:1167-92.

13 Goel M, Wong ND, Eisenberg H, Hagar J, Kelly D, Tobis JM. Risk fac tor correlates of coronary calcium as evaluated by ultrafast computed tomography. Am $\mathcal{F}$ Cardiol 1992;70:977-80.

14 Janowitz WR, Agatston AS, Kaplan G, Viamonte M. Differences in prevalence and extent of coronary artery calcium detected by ultrafast computed tomography in asymptomatic men and women. $A m \mathcal{F}$ Cardiol 1993;72:247-54

15 Detrano R, Wong N, Tang W, Brezden O, Georgiou D, Brundage B. Prognostic significance of cardiac cinefluoroscopy for coronary calcific deposits in a high risk asymptomatic population. $\mathcal{F} \mathrm{Am}$ Coll Cardiol (in press).

16 Wong ND, Vo A, Abrahamson D, Eisenberg H, Tobis JM. Prediction of coronary events from noninvasive calcium screening by ultrafast CT [abstr]. Circulation 1993;88:I-15.

17 Cumming G, Samm J, Borsyk L, Kich L. Electrocardiographic change during exercise in asymptomatic men: 3 year follow-up. Can Med Assoc f 1975;112:578-81.

18 Detrano R, Froelicher V. A logical approach to screening for coronary disease. Ann Intern Med 1987;106:846-52.

19 Agatston AS, Janowitz WR, Hildner FJ, Zusmer NR, Viamonte M, Detrano R. Quantification of coronary artery calcium using ultrafas computed tomography. 7 Am Coll Cardiol 1990;15:827-32.

20 Wun $\mathrm{H}$, Detrano $\mathrm{R}$, Kang X, Mahaisavariya O, Nickerson S, Molloi S Geometric instability of ultrafast computed tomographic coronary calcium scores due to grey scale non-uniformities. Proceedings of the Society for Photooptical Instrumentation Engineers. 1994;2168:42-65.

21 Tang W, Detrano R, Kang X, Garner D, Nickerson S, Desimone P, Mahaisavariya $P$, Brundage $B$. The effects of particle size, slice thickness and reconstruction algorithm on coronary calcium quantitation using ultrafast computed tomography. Proceedings of the Society for Photooptical Instrumentation Engineers. 1994; 2168:66-72.

22 Detrano R, Kang X, Mahaisavariya P, Garner D, Georgiou D, Molloi S, Brundage B. Post hoc correction for partial voluming errors in the quantification of coronary artery calcium. Advances in ultrafast CT. 1993, Imatron;45.

23 Detrano R. New ultrafast CT algorithm accurately predicts mass of coronary calcium phosphate [abstr]. F Am Coll Cardiol 1994;180.

24 Kragel A, Gertz D, Roberts W. Morphologic comparison of frequency and types of acute lesions in the major epicardial coronary arteries in and types of acute lesions in the major epicardial coronary arteries instable angina pectoris, sudden coronary

25 Janowitz WR, Agatston AS, Viamonte M Jr. Comparison of serial quantitative evaluation of calcified coronary artery plaque by ultrafast computed tomography in persons with and without obstructive coronary artery disease. Am $\mathcal{F}$ Cardiol 1991;68:1-6.

26 Davies MJ, Thomas AC. Plaque fissuring - the cause of acute myocardial infarction, sudden ischaemic death, and crescendo angina. Br Heart $f$ 1985;53:363-73.

27 Cheng GC, Loree HM, Kamm RD, Fishbein MC, Lee RT. Distribution of circumferential stress in ruptured and stable atherosclerotic lesions. A structural analysis with histopathological correlation. Circulation 1993;87:1 179-87.

28 Doherty $T$, Detrano R. Coronary arterial calcification as an active process: a new perspective on an old problem. Calcif Tiss Int 1994;54: 224-30.

29 Mintz G, Potkin B, Keren G, Stater L Pichard A, Kent $K$, et al. Intravascular ultrasound evaluation of the effect of rotational atherectomy in obstructive atherosclerotic coronary artery disease. Circulation 1992;86:1383-93

30 De lezo J, Romero M, Medina A, Pan M, Pavlovic D, Vaamonde R, et al. Intracoronary ultrasound assessment of directional coronary atherectomy: immediate and follow-up findings. F Am Coll Cardiol 1993; 21:298-307.

31 McHenry P, Richmond H, Weisenberger B, Rodway J, Perry G, Jordan J. Evaluation of abnormal exercise electrocardiograms in apparently healthy subjects: labile repolarization (ST-T) abnormalities as a cause of false positive responses. Am $\mathcal{F}$ Cardiol 1981;47:1152-60.

32 Marise J, Duval R, Dalai J. Frequency of oral estrogen replacement the apy in women with normal and abnormal exercise electrocardiogram and normal coronary arteries by angiogram. Am f Cardiol 1993;72: $1197-8$.

33 Harach HR, Fransilla KO, Waesniius VM. Occult papillary carcinoma of the thyroid: abnormal finding in Finland: a systematic autopsy study. Cancer 1985;56:531-8. 